\title{
Background heterogeneity and other uncertainties in estimating urban methane flux: results from the Indianapolis Flux Experiment (INFLUX)
}

\author{
Nikolay V. Balashov ${ }^{1,3, a}$, Kenneth J. Davis ${ }^{2}$, Natasha L. Miles ${ }^{2}$, Thomas Lauvaux ${ }^{2,4}$, Scott J. Richardson ${ }^{2}$, \\ Zachary R. Barkley ${ }^{2}$, and Timothy A. Bonin ${ }^{5,6}$ \\ ${ }^{1}$ NASA Postdoctoral Program, Universities Space Research Association, 7178 Columbia Gateway Drive, \\ Columbia, MD, 21046, USA \\ ${ }^{2}$ The Pennsylvania State University, University Park, Pennsylvania, USA \\ ${ }^{3}$ NASA Global Modeling and Assimilation Office (GMAO), Goddard Space Flight Center, Greenbelt, MD, 20771, USA \\ ${ }^{4}$ Laboratory of Climate Sciences and Environment, Gif-sur-Yvette, France \\ ${ }^{5}$ Cooperative Institute for Research in Environmental Sciences, Boulder, Colorado, USA \\ ${ }^{6}$ Chemical Sciences Division, National Oceanic and Atmospheric Administration, Boulder, Colorado, USA \\ ${ }^{a}$ formerly at: The Pennsylvania State University, University Park, Pennsylvania, USA
}

Correspondence: Nikolay V. Balashov (nvb5011@psu.edu, nikolay.v.balashov@ nasa.gov) and

Kenneth J. Davis (kjd10@psu.edu)

Received: 19 January 2019 - Discussion started: 13 March 2019

Revised: 25 February 2020 - Accepted: 4 March 2020 - Published: 17 April 2020

\begin{abstract}
As natural gas extraction and use continues to increase, the need to quantify emissions of methane $\left(\mathrm{CH}_{4}\right)$, a powerful greenhouse gas, has grown. Large discrepancies in Indianapolis $\mathrm{CH}_{4}$ emissions have been observed when comparing inventory, aircraft mass balance, and tower inverse modeling estimates. Four years of continuous $\mathrm{CH}_{4}$ mole fraction observations from a network of nine towers as a part of the Indianapolis Flux Experiment (INFLUX) are utilized to investigate four possible reasons for the abovementioned inconsistencies: (1) differences in definition of the city domain, (2) a highly temporally variable and spatially non-uniform $\mathrm{CH}_{4}$ background, (3) temporal variability in $\mathrm{CH}_{4}$ emissions, and (4) $\mathrm{CH}_{4}$ sources that are not accounted for in the inventory. Reducing the Indianapolis urban domain size to be consistent with the inventory domain size decreases the $\mathrm{CH}_{4}$ emission estimation of the inverse modeling methodology by about $35 \%$, thereby lessening the discrepancy and bringing total city flux within the error range of one of the two inventories. Nevertheless, the inverse modeling estimate still remains about $91 \%$ higher than inventory estimates. Hourly urban background $\mathrm{CH}_{4}$ mole fractions are shown to be spatially heterogeneous and temporally variable. Variability in
\end{abstract}

background mole fractions observed at any given moment and a single location could be up to about 50 ppb depending on a wind direction but decreases substantially when averaged over multiple days. Statistically significant, longterm biases in background mole fractions of $2-5 \mathrm{ppb}$ are found from single-point observations for most wind directions. Boundary layer budget estimates suggest that Indianapolis $\mathrm{CH}_{4}$ emissions did not change significantly when comparing 2014 to 2016 . However, it appears that $\mathrm{CH}_{4}$ emissions may follow a diurnal cycle, with daytime emissions (12:00-16:00 LST) approximately twice as large as nighttime emissions (20:00-05:00 LST). We found no evidence for large $\mathrm{CH}_{4}$ point sources that are otherwise missing from the inventories. The data from the towers confirm that the strongest $\mathrm{CH}_{4}$ source in Indianapolis is South Side landfill. Leaks from the natural gas distribution system that were detected with the tower network appeared localized and nonpermanent. Our simple atmospheric budget analyses estimate the magnitude of the diffuse natural gas source to be $70 \%$ higher than inventory estimates, but more comprehensive analyses are needed. Long-term averaging, spatially extensive upwind mole fraction observations, mesoscale atmo- 
spheric modeling of the regional emissions environment, and careful treatment of the times of day are recommended for precise and accurate quantification of urban $\mathrm{CH}_{4}$ emissions.

\section{Introduction}

From the beginning of the Industrial Revolution to 2011, atmospheric methane $\left(\mathrm{CH}_{4}\right)$ mole fractions increased by a factor of 2.5 due to anthropogenic processes such as fossil fuel production, waste management, and agricultural activities (Ciais et al., 2013; Hmiel et al., 2020). The increase in $\mathrm{CH}_{4}$ is a concern as it is a potent greenhouse gas $(\mathrm{GHG})$ with a global warming potential 28-34 times greater than that of $\mathrm{CO}_{2}$ over a period of 100 years (Myhre et al., 2013). The magnitudes of component $\mathrm{CH}_{4}$ sources responsible for the recent increase in the global $\mathrm{CH}_{4}$ budget are not well understood, with theories attributing these changes to biogenic, thermogenic, and pyrogenic emissions or a decline in the atmospheric $\mathrm{CH}_{4}$ sink (Nisbet et al., 2016, 2019; Saunois et al., 2016; Hmiel et al., 2020). Improved understanding of $\mathrm{CH}_{4}$ emissions is needed (National Academies of Sciences and Medicine, 2018).

In particular, the estimates of continental US anthropogenic $\mathrm{CH}_{4}$ emissions disagree. Inventories from the Environment Protection Agency (EPA) and Emissions Database for Global Atmospheric Research (EDGAR) in 2008 reported emission values of 19.6 and $22.1 \mathrm{Tg} \mathrm{C} \mathrm{yr}^{-1}$ (U.S. EPA, 2013; European Commission Joint Research Centre and Netherlands Environmental Assessment Agency, 2010). However, top-down methodologies using aircraft and inverse modeling frameworks found emission values of $32.4 \pm$ $4.5 \mathrm{Tg} \mathrm{C} \mathrm{yr}^{-1}$ for 2004 and $33.4 \pm 1.4 \mathrm{Tg} \mathrm{C} \mathrm{yr}^{-1}$ for $2007-$ 2008 respectively (Kort et al., 2008; Miller et al., 2013). Underestimation of natural gas (NG) production and agricultural sources are possible reasons for this disagreement (Miller et al., 2013; Brandt et al., 2014; Jeong et al., 2014). Efforts to reconcile GHG emissions estimates using atmospheric methods and inventory assessment have sometimes succeeded (Schuh et al., 2013; Zavala-Araiza et al., 2015; Turnbull et al., 2019) when careful attention is given to the details of each method, and targeted atmospheric data are available. A recent synthesis of emissions from the US NG supply chain demonstrated similar success and concluded that current inventory estimates of emissions from US NG production are too low and that emission from NG distribution is one of the greatest remaining sources of uncertainty in the NG supply chain (Alvarez et al., 2018).

Due to the uncertainties in $\mathrm{CH}_{4}$ emissions from NG distribution it is natural that urban emissions are of interest as well. For example, two studies (McKain et al., 2015; Hendrick et al., 2016) indicate that $\sim 60 \%-100 \%$ of Boston $\mathrm{CH}_{4}$ emissions are attributable to the NG distribution system. Recent studies of urban $\mathrm{CH}_{4}$ emissions in California indicate that the
California Air Resources Board (CARB) inventory tends to underestimate the actual $\mathrm{CH}_{4}$ urban fluxes, possibly due to fugitive emissions from NG infrastructures in urban environments (Wunch et al., 2009; Jeong et al., 2016, 2017). The accuracy and precision of atmospheric estimates of urban $\mathrm{CH}_{4}$ emissions are limited by available atmospheric observations (Townsend-Small et al., 2012), potential source magnitude variability with time (Jackson et al., 2014; Lamb et al., 2016), errors in atmospheric transport modeling (Hendrick et al., 2016; Deng et al., 2017; Sarmiento et al., 2017), and complexity in atmospheric background conditions (Cambaliza et al., 2014; Karion et al., 2015; Heimburger et al., 2017). In this work, detailed analysis of urban $\mathrm{CH}_{4}$ mole fractions is performed for the city of Indianapolis to better understand the aforementioned uncertainties of urban $\mathrm{CH}_{4}$ emissions.

The Indianapolis Flux Experiment (INFLUX; Davis et al., 2017) is a testbed for improving the quantification of urban GHGs emissions and their variability in space and time. INFLUX (http://influx.psu.edu, last access: 8 April 2020) is located in Indianapolis partly because of its isolation from other urban centers and the flat Midwestern terrain. It includes a very dense GHG monitoring network, comprised of irregular in situ aircraft measurements (Heimburger et al., 2017; Cambaliza et al., 2014), continuous in situ observations from communications towers using cavity ring-down spectroscopy (Richardson et al., 2017; Miles et al., 2017a), and automated flask sampling systems for the quantification of a wide variety of trace gases (Turnbull et al., 2015). Meteorological sensors include a Doppler lidar providing continuous boundary layer depth and wind profiles and tower-based eddy covariance measurements of the fluxes of momentum and sensible and latent heat (Sarmiento et al., 2017). The network is designed for emissions quantification using top-down methods such as tower-based inverse modeling (Lauvaux et al., 2016) and aircraft mass balance estimates (Cambaliza et al., 2015).

Lamb et al. (2016) compared Indianapolis $\mathrm{CH}_{4}$ emissions estimates from a variety of approaches, specifically inventory, aircraft mass balances, and inverse modeling. The results revealed large mean differences among the city fluxes estimated from these methods (Fig. 1). In general, the inventory methods arrived at lower estimates of emissions compared to the atmospheric or top-down approaches. $\mathrm{CH}_{4}$ fluxes calculated using the aircraft mass balance technique varied considerably between flights, more than would be expected from propagation of errors of the component measurements (Cambaliza et al., 2014; Lamb et al., 2016). The atmospheric inverse estimate was significantly higher than the inventory and some of the aircraft-derived values.

Biogenic emissions from the city are dominated by a landfill close to downtown, and these emissions are thought to be fairly well known (GHG reporting program), although evidence of possible variability in landfill emissions exists from Cambaliza et al. (2015), which used aircraft mass balance on five different occasions to calculate $\mathrm{CH}_{4}$ flux from this 


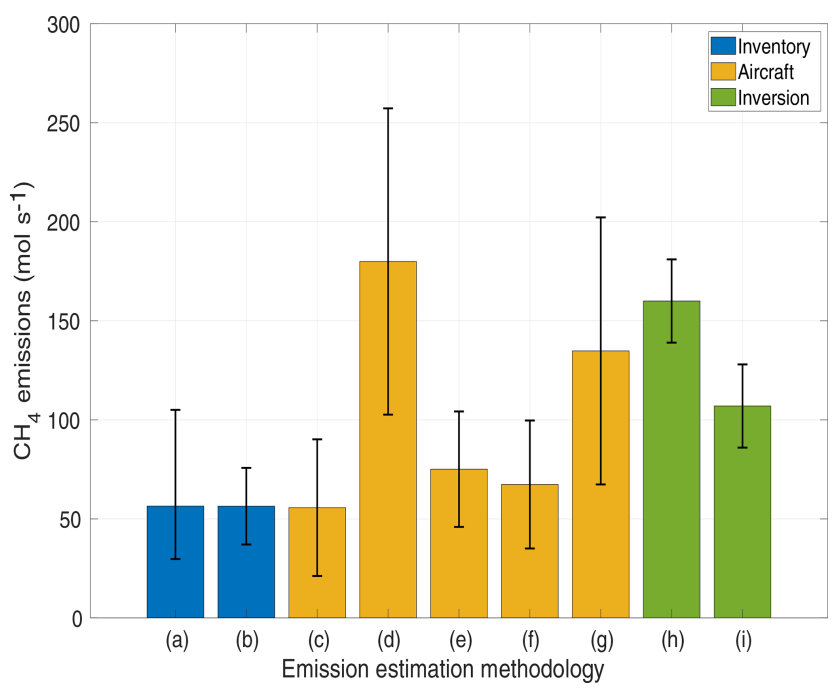

Figure 1. Various estimates of $\mathrm{CH}_{4}$ emissions at Indianapolis. (a, b) Bottom-up estimates of $\mathrm{CH}_{4}$ emissions conducted by Lamb et al. (2016) in 2013 and Maasakkers et al. (2016) based on the EPA 2012 inventory, respectively. Error bars show $95 \%$ confidence intervals (for more details see abovementioned articles). (c-g) Top-down evaluations of $\mathrm{CH}_{4}$ emissions with aircraft from various flight campaigns where (c) contains five flights over March-April of 2008, (d) contains three flights over November-January of 2008-2009, (e) contains five flights over April-July of 2011, (f) contains nine flights from November-December, 2014, and (g) contains the same five flights over April-July of 2011 as in (e) but uses different methodology. Methodologies for (c-f) are described in Lamb et al. (2016) and the methodology for ( $\mathbf{g}$ ) is described in Cambaliza et al. (2015). Error bars show $95 \%$ confidence intervals (for more details see abovementioned articles). (h, i) Top-down evaluations of $\mathrm{CH}_{4}$ emissions for 2012-2013 using tower inversion modeling methodology with two different domains, where (h) uses the full domain of Fig. 2 and (i) uses only the Marion County domain of Fig. 2. The inversion methodology and $95 \%$ confidence intervals are described in detail in Lamb et al. (2016).

landfill. Uncertainty in total city emissions is mainly driven by the uncertainty in thermogenic emissions, which are hypothesized to emerge largely from the NG distribution system (Mays et al., 2009; Cambaliza et al., 2015; Lamb et al., 2016). In this study, we explore potential explanations for the discrepancies in $\mathrm{CH}_{4}$ emissions estimates from Indianapolis and posit methods and recommendations for the study of $\mathrm{CH}_{4}$ emissions from other urban centers.

We examine four different potential explanations for the $\mathrm{CH}_{4}$ flux discrepancies reported in Lamb et al. (2016): (1) inconsistent geographic boundaries between top-down and bottom-up studies, (2) heterogeneity in the urban-scale $\mathrm{CH}_{4}$ background and (3) temporal variability in urban emissions, which is not captured by the existing top-down studies, and (4) $\mathrm{CH}_{4}$ sources that are not accounted for in the inventories. Well-calibrated $\mathrm{CH}_{4}$ sensors on the INFLUX tower network (Miles et al., 2017a) collected continuous $\mathrm{CH}_{4}$ ob- servations from 2013 to 2016 and provide a unique opportunity to explore these issues.

\section{Methods}

\subsection{Experimental site}

This study uses data from a tower-based GHG observational network located in the city and surrounding suburbs of Indianapolis, Indiana, in the Midwestern US. Prior studies have used varying definitions for the region of Indianapolis (Cambaliza et al., 2015; Lamb et al., 2016). In this work, we follow Gurney et al. (2012) and define Indianapolis as the area of Marion County. The flat terrain of the region simplifies interpretation of the atmospheric transport. The land-surface heterogeneity inherent in the urban environment (building roughness, spatial variations in the surface energy balance) does have a modest influence on the wind and boundary layer depth within the city compared to nearby rural areas (Sarmiento et al., 2017).

Figure 2 shows two domains that have been used for the evaluation of Indianapolis $\mathrm{CH}_{4}$ emissions (Lamb et al., 2016; Lauvaux et al., 2016). The first domain is the whole area shown in the figure enclosing both Indianapolis and places that lie outside of its boundaries. This domain was used for the inversion performed in Lamb et al. (2016). The second domain is Marion County, outlined with a green dashed line. It is assumed here that this domain is much more representative of the actual Indianapolis municipal boundaries as this area encompasses the majority of the urban development associated with the city of Indianapolis (Gurney et al., 2012). The larger domain has three additional landfills that, based on the EPA gridded inventory (Maasakkers et al., 2016), increase Indianapolis $\mathrm{CH}_{4}$ emissions by about $50 \%$ when compared to the smaller domain. The inversion explained in Lamb et al. (2016) has been rerun for two of the domains mentioned above and the results (Fig. 1) have been reexamined.

\subsection{INFLUX tower network}

The continuous GHG measurements from INFLUX are described in detail in Richardson et al. (2017). The measurements were made using wavelength-scanned cavity ring down spectrometers (CRDSs, Picarro, Inc., models G2301, G2302, G2401, and G1301), installed at the base of existing communications towers, with sampling tubes secured as high as possible on each tower (39-136 m above ground level (a.g.l.); Miles et al., 2017a). A few towers also included measurements at $10 \mathrm{~m}$ a.g.l. and one or two intermediate levels. While INFLUX tower in situ measurements began in September 2010, here we focus on the $\mathrm{CH}_{4}$ measurements from 2013-2016. From June through December 2012, there were two or three towers with operational $\mathrm{CH}_{4}$ measurements. By July 2013, five towers included measurements of 


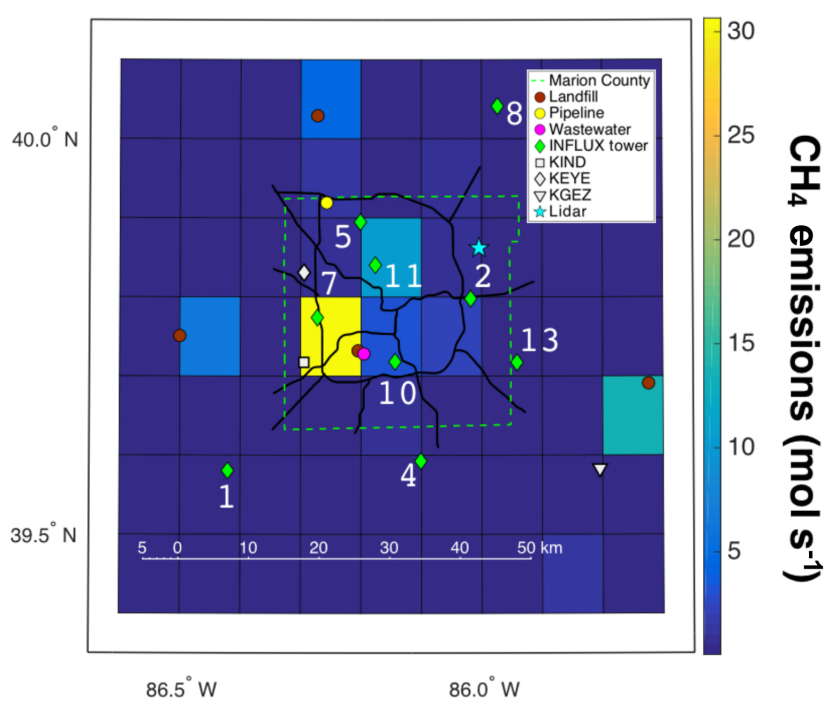

Figure 2. Map of the primary roads in Indianapolis, INFLUX towers, lidar system, weather stations, and a few $\mathrm{CH}_{4}$ point sources plotted over the gridded $\mathrm{CH}_{4}$ emissions ( $\mathrm{mol} \mathrm{s}^{-1}$ ) from the EPA 2012 inventory (Maasakkers et al., 2016). The gridded map of emissions includes emissions from the mentioned point sources; their position is provided to aid in interpretation of the observations. The dashed bright green line denotes Marion County borders.

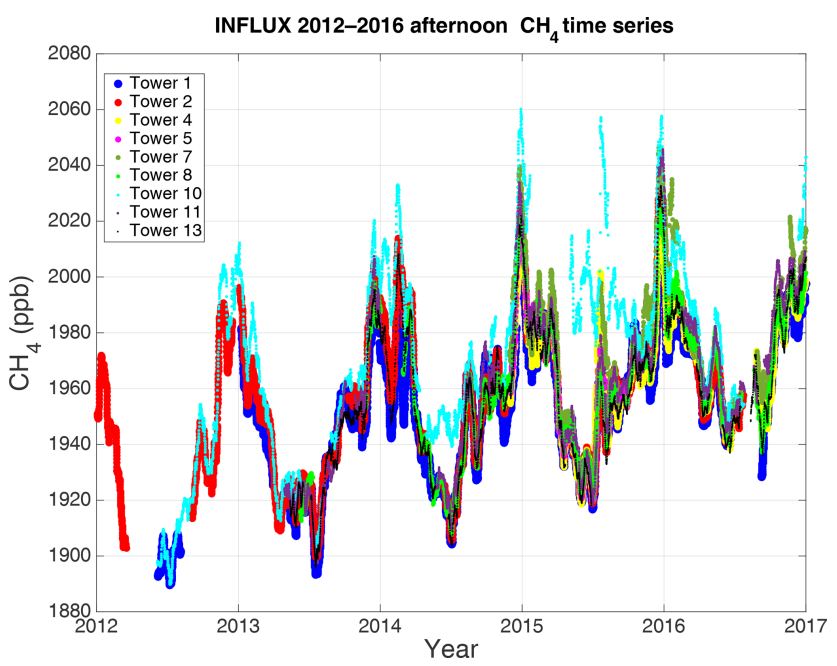

Figure 3. The $20 \mathrm{~d}$ running average of afternoon (12:00-16:00 LST; the hours are inclusive) $\mathrm{CH}_{4}$ mole fractions as measured by the INFLUX tower network (highest available height is used) from 2012 through 2016.

$\mathrm{CH}_{4}$, and throughout the majority of the years 2015-2016 there were eight INFLUX towers with $\mathrm{CH}_{4}$ measurements (Fig. 3). Comparisons between flask and in situ measurements and round-robin-style testing indicated compatibility across the tower network of $0.6 \mathrm{ppb} \mathrm{CH}_{4}$ (Richardson et al., 2017). In this study we use hourly means of $\mathrm{CH}_{4}$.

\subsection{Meteorological data}

Wind speed and direction were measured at the Indianapolis International Airport (KIND), Eagle Creek Airpark (KEYE), and Shelbyville Municipal Airport (KGEZ). The data used are hourly values from the Integrated Surface Dataset (ISD) (https://www.ncdc.noaa.gov/isd, last access: 8 April 2020) and $5 \mathrm{~min}$ values directly from the Automated Surface $\mathrm{Ob}$ serving System (ASOS). A complete description of ASOS stations is available at https://www.weather.gov/media/asos/ aum-toc.pdf (last access: 8 April 2020). The accuracy of the wind speed measurements are $\pm 1 \mathrm{~m} \mathrm{~s}^{-1}$ or $5 \%$ (whichever is greater) and the accuracy of the wind direction is $5^{\circ}$ when the wind speed is $\geq 2.6 \mathrm{~m} \mathrm{~s}^{-1}$. The anemometers are located at about $10 \mathrm{~m}$ a.g.l. The wind data reported in ISD are given for a single point in time recorded within the last $10 \mathrm{~min}$ of an hour and are closest to the value at the top of the hour.

The planetary boundary layer height (BLH) was determined from a Doppler lidar deployed in Lawrence, Indiana, about $15 \mathrm{~km}$ to the northeast of downtown. The lidar is a Halo Streamline unit, which was upgraded to have extended range capabilities in January 2016. The lidar continuously performs a sequence of conical, vertical-slice, and staring scans to measure profiles of the mean wind, turbulence, and relative aerosol backscatter. All of these measurements are combined using a fuzzy-logic technique to automatically determine the BLH continuously every $20 \mathrm{~min}$ (Bonin et al., 2018). The BLH is primarily determined from the turbulence measurements, but the wind and aerosol profiles are also used to refine the BLH estimate. The BLHs are assigned quality-control flags that can be used to identify times when the determined BLH is unreliable, such as when the air is exceptionally clean, the BLH is below a minimum detectable height, or clouds and fog that attenuate the lidar signal exist. Additional details about the algorithm and the lidar operation for INFLUX are provided in Bonin et al. (2018). Doppler lidar measurements are available at https://www.esrl.noaa.gov/csd/projects/influx/ (last access: 8 April 2020).

\subsection{Urban methane background}

Both the aircraft mass balance and inverse modeling methodologies rely on an accurate estimation of the urban $\mathrm{CH}_{4}$ enhancement relative to the urban $\mathrm{CH}_{4}$ background in order to produce a reliable flux estimate (Cambaliza et al., 2014; Lamb et al., 2016). The $\mathrm{CH}_{4}$ mole fraction enhancement is defined as

$C_{\text {enhancement }}=C_{\text {downwind }}-C_{\mathrm{bg}}$,

where $C_{\text {downwind }}$ is the $\mathrm{CH}_{4}$ mole fraction measured downwind of a source and $C_{\text {bg }}$ is the $\mathrm{CH}_{4}$ background mole fraction, which can be measured upwind of the source, but this is not necessary. Background, as defined in this body of literature, is a mole fraction measurement that does not con- 
tain the influence of the source of interest, but which is assumed to accurately represent mole fractions that are upwind of the source of interest and measured simultaneously with the downwind mole fractions.

The aircraft mass balance studies of Indianapolis mentioned used two main methods to determine a background value. The first method calculates an average of the aircraft transect edges that lie outside of the city domain (Cambaliza et al., 2014). In the second approach, a horizontally varying background is introduced by linearly interpolating median background values of each of the transect edges (Heimburger et al., 2017). In theory there is also a third method that uses an upwind transect as a background field, but in the studies above it was assumed that the edges are representative of an upwind flow. In the case of an inversion, it is common to pick a tower that is located away from urban sources and has on average the smallest overall enhancement (Lauvaux et al., 2016). Because choosing the background involves a degree of subjectivity (Heimburger et al., 2017) we consider how these choices may influence emission estimates and introduce error, both random and systematic, using data from the INFLUX tower network.

Using tower network data from November 2014 through the end of 2016, two $\mathrm{CH}_{4}$ background fields are generated for the city of Indianapolis based on two different sets of criteria. The notion is based on the fact that a choice of background is currently rather arbitrary in the literature (Heimburger et al., 2017), and at every point in time it is possible to choose multiple background values that are equally acceptable for the flux estimation. In our case both approaches identify a tower suitable to serve as a background for each of the eight wind directions (N, NE, E, SE, S, SW, W, NW), where an arc of $45^{\circ}$ represents a direction (e.g., winds from $\mathrm{N}$ are between 337.5 and $22.5^{\circ}$ ). Estimating background for different wind directions is implemented to more accurately represent upwind flow that is hopefully not contaminated by local sources.

Criterion 1 corresponds to a typical choice of a background in a case of tower inversion and is based on the concept that the lowest $\mathrm{CH}_{4}$ mole fraction measured at any given time is not affected by the city sources and therefore is a viable approximation of the background $\mathrm{CH}_{4}$ mole fractions outside of the city (Miles et al., 2017a; Lauvaux et al., 2016). Given this assumption, the tower with the lowest median of the $\mathrm{CH}_{4}$ enhancement distribution (calculated by assuming the lowest measurement among all towers at a given hour as a background) for each of the wind directions over the November 2014 through December 2016 time period is chosen as a background site (Miles et al., 2017a). Criterion 2 requires that the tower is outside of Marion County (outside of the city boundaries) and is not downwind of any known regional $\mathrm{CH}_{4}$ source (Fig. 2). For some wind directions, there are multiple towers that could qualify as a background; we pick towers in such a manner that they are different for each criterion given a wind direction in order to calculate the er-
Table 1. INFLUX towers used to estimate $\mathrm{CH}_{4}$ background based on two different criteria. Numbers in bold indicate towers chosen to generate a background field when multiple options are possible (for more details see discussion). In short, criterion 1 uses towers with the lowest mean $\mathrm{CH}_{4}$ for a specific wind direction, and criterion 2 uses towers outside of Marion County and not downwind of large sources (including the city as a whole).

\begin{tabular}{lrr}
\hline Wind direction & \multicolumn{2}{c}{$\mathrm{CH}_{4}$ background towers } \\
\cline { 2 - 3 } & Criterion 1 & Criterion 2 \\
\hline North (N) & 8 & $\mathbf{1 3}, 8$ \\
Northeast (NE) & 8 & $\mathbf{1 3}, 8,2$ \\
East (E) & $\mathbf{2 ,} 8$ & $\mathbf{8}, 4,1,2$ \\
Southeast (SE) & 1 & $\mathbf{8}, 13,4,1$ \\
South (S) & 1 & $\mathbf{4 , 1 3 , 1}$ \\
Southwest (SW) & 13 & $\mathbf{1}, 4$ \\
West (W) & 1 & $\mathbf{4}, 1$ \\
Northwest (NW) & 1 & $\mathbf{8}, 1$ \\
\hline
\end{tabular}

ror associated with the use of different but acceptable backgrounds. The towers used for both criteria and for each of the eight wind directions are displayed in Table 1. Quantifying differences between these two backgrounds allows for an opportunity to better understand the degree of uncertainty that exists in the atmospheric $\mathrm{CH}_{4}$ background at Indianapolis.

To make the comparison as uniform as possible only data from 12:00-16:00 LST are utilized (all hours are inclusive) when the boundary layer is typically well mixed (Bakwin et al., 1998). A lag 1 autocorrelation is found between 12:00 and 16:00LST; i.e., the hourly afternoon data are correlated to the next hour, but the correlation is not significant for samples separated by $2 \mathrm{~h}$ or more. Therefore, hours 13:00 and 15:00 LST are eliminated to satisfy the independence assumption for hourly samples. Furthermore, we make an assumption that the data satisfy steady-state conditions. If the difference between consecutive hourly wind directions exceeds $30^{\circ}$ or the difference between hours 16:00 and 12:00 LST exceeds $40^{\circ}$, the day is eliminated. Days with average wind speeds below $2 \mathrm{~m} \mathrm{~s}^{-1}$ are also eliminated due to slow transport across the city (the transit time from tower 1 to tower 8 is about $7 \mathrm{~h}$ at a wind speed of $2 \mathrm{~m} \mathrm{~s}^{-1}$ ).

\subsection{Frequency and bivariate polar plots}

Frequency and bivariate polar plots are used in this work to gain more knowledge regarding $\mathrm{CH}_{4}$ background variability based on criteria 1 and 2, and to identify sources located within the city. To generate these polar plots, we use the openair package (from $\mathrm{R}$ programming language) created specifically for air quality data analysis (Carslaw and Ropkins, 2012). Bivariate and frequency polar plots indicate the variability of a pollutant concentration at a receptor (such as an observational tower) as a function of wind speed and wind 
direction, preferably measured at the location of the receptor or within several kilometers of the receptor. The frequency polar plot is generated by partitioning the $\mathrm{CH}_{4}$ hourly data into the wind speed and direction bins of $1 \mathrm{~m} \mathrm{~s}^{-1}$ and $10^{\circ}$ respectively. To generate bivariate polar plots, wind components $u$ and $v$ are calculated for hourly $\mathrm{CH}_{4}$ mole fraction values, which are fitted to a surface using a generalized additive model (GAM) framework in the following way:

$\sqrt{C}=\beta+s(u, v)+\epsilon$,

where $C$ is the $\mathrm{CH}_{4}$ mole fraction transformed by a square root to improve model diagnostics such as a distribution of residuals, $\beta$ is mean of the response, $s$ is the isotropic smoothing function of the wind components $u$ and $v$, and $\epsilon$ is the residual. For more details on the model see Carslaw and Beevers (2013).

\subsection{Temporal variability and approximate flux estimation}

Temporal variability in urban $\mathrm{CH}_{4}$ emissions may play an important role in the corresponding emissions quantification procedures. Lamb et al. (2016) suggested that such temporal variability might partially explain the differences among $\mathrm{CH}_{4}$ flux estimates shown in Fig. 1. If temporal variability of $\mathrm{CH}_{4}$ emissions exists within the city, disagreements in the $\mathrm{CH}_{4}$ flux between studies could be attributed to differences in their sampling period. Because the INFLUX tower data at Indianapolis contain measurements at all hours of the day over multiple years, we can utilize this dataset to better understand the temporal variability in methane emissions in the city.

We apply a simplified atmospheric boundary layer budget, not to estimate precisely the actual city emissions, but rather to evaluate temporal variability of the emissions. We begin by assuming $\mathrm{CH}_{4}$ emissions $Q_{\mathrm{a}}$ (mass per unit time per unit area) are not chemically active and are constant over a distance $\Delta x$ spanning a significant portion of the city. The next assumption is that a $\mathrm{CH}_{4}$ plume measured downwind of the city is well mixed within a layer of depth $H$ (which is the same as BLH). We treat wind speed $u$ as constant within the layer for every hour considered. Given the abovementioned assumptions we can write a continuity equation describing mass conservation of $\mathrm{CH}_{4}$ concentration $C$ within a box in the following fashion:

$\Delta x H \frac{\partial C}{\partial t}=\Delta x Q_{\mathrm{a}}+u H\left(C_{\mathrm{b}}-C\right)+\Delta x \frac{\partial H}{\partial t}\left(C_{\mathrm{a}}-C\right)$,

where $C_{\mathrm{b}}$ is the $\mathrm{CH}_{4}$ concentration upwind of the city (or background), and $C_{\mathrm{a}}$ is the $\mathrm{CH}_{4}$ concentration above the mixed layer (Hanna et al., 1982; Arya, 1999; Hiller et al., 2014). The left-hand side of the equation represents the change in $\mathrm{CH}_{4}$ concentration with time, $\Delta x Q_{\mathrm{a}}$ denotes a constant $\mathrm{CH}_{4}$ source over the distance $\Delta x, u H\left(C_{\mathrm{b}}-C\right)$ indicates a change of $\mathrm{CH}_{4}$ concentration due to horizontal advection, and finally the $\Delta x \frac{\partial H}{\partial t}\left(C_{\mathrm{a}}-C\right)$ term accounts for the vertical advection and encroachment processes that result from changing BLH. By assuming steady-state conditions $\left(\frac{\partial C}{\partial t}=0\right.$ and $\left.\frac{\partial H}{\partial t}=0\right)$, the equation can be simplified to

$Q_{\mathrm{a}}=\frac{u H\left(C-C_{\mathrm{b}}\right)}{\Delta x}$.

We use Eq. (4) to estimate hourly $\mathrm{CH}_{4}$ emissions $\left(Q_{\mathrm{a}}\right)$ from Indianapolis (see assumptions in the paragraph below) given hourly averaged data of $H$ from the lidar positioned in the city, wind speed $(u)$ from the local weather stations, and upwind $\left(C_{\mathrm{b}}\right)$ and downwind $(C) \mathrm{CH}_{4}$ mole fractions measured (and then converted to concentrations) at towers 1 , 8 , and 13 (depending on a wind direction) using data from heights of 40, 41, and $87 \mathrm{~m}$ respectively (see Fig. 2).

The $\mathrm{CH}_{4}$ concentrations are derived from $\mathrm{CH}_{4}$ mole fractions by approximating average molar density of dry air (in $\mathrm{mol} \mathrm{m}{ }^{-3}$ ) within the boundary layer for every hour of the day, where variability of pressure with altitude is calculated using the barometric formula, and it is assumed that temperature decreases with altitude by $6.5 \mathrm{~K}$ per kilometer. The hourly surface data for pressure and temperature are taken from KIND weather station. The difference between concentrations $C$ and $C_{\mathrm{b}}$ is instantaneous and not lagged, where $C_{\mathrm{b}}$ represents an air parcel entering the city and $C$ represents the same air parcel exiting the city (Turnbull et al., 2015). The $\mathrm{CH}_{4}$ enhancements $\left(\mathrm{C}-\mathrm{C}_{\mathrm{b}}\right)$ are estimated for daytime by averaging observations spanning 12:00-16:00 LST and for nighttime by averaging observations spanning 20:0005:00 LST. These time periods are based on lidar estimations of when on average $H$ varies the least. Each daytime and nighttime were required to contain at least 3 and $9 \mathrm{~h}$ of $\mathrm{CH}_{4}$ values respectively for averaging to occur, otherwise they were eliminated from the computation process. Observations when $H$ is below $100 \mathrm{~m}$ are not used to avoid the cases when measurements from towers may be above the boundary layer. In order to better achieve the assumption that the boundary layer is fully mixed (especially at night), all hours with wind speeds below $4 \mathrm{~m} \mathrm{~s}^{-1}$ are eliminated (Van De Wiel et al., 2012). To approximate the emissions of the whole city we need to know the approximate area of the city and the distance over which the plume is affected by the city $\mathrm{CH}_{4}$ sources. The area of the city is about $1024 \mathrm{~km}^{2}$ (the area of Marion County) and the length that plume traverses when it is over the city ranges from 32 to $35 \mathrm{~km}$ depending on which downwind tower is used. We assume that $\mathrm{CH}_{4}$ measurements at towers 8 and 13 are representative of a vertically wellmixed city plume as the towers are located outside of the city boundaries and allow for sufficient vertical mixing to occur. For $\mathrm{S}$ and $\mathrm{SW}$ wind directions tower 8 observations are used to represent downwind conditions, with background observations coming from towers 1 and 13, respectively (based on criterion 1 shown in Table 1). For $\mathrm{W}$ wind direction, tower 13 observations represent the downwind with background obtained from tower 1 . The wind direction is required to be 
sustained for at least $2 \mathrm{~h}$, otherwise the data point is eliminated.

\subsection{Indianapolis $\mathrm{CH}_{4}$ sources}

Only a few known $\mathrm{CH}_{4}$ point sources exist within Indianapolis (Cambaliza et al., 2015; Lamb et al., 2016). The South Side landfill (SSLF), located near the center of the city, is thought to be the largest point source in the city, with emissions ranging between about $28 \mathrm{~mol} \mathrm{~s}^{-1}$ (inventory from Maasakkers et al., 2016, GHG reporting program, and inverse estimates from ground-based mobile sampling employed in Lamb et al., 2016) and $45 \mathrm{~mol} \mathrm{~s}^{-1}$ (aircraft; Cambaliza et al., 2015) depending on an emission estimation methodology. However, using Cambaliza et al. (2015) aircraft data and applying a different background formulation, Lamb et al. (2016) found emission values of SSLF closely agreeing with the $28 \mathrm{~mol} \mathrm{~s}^{-1}$ estimate. SSLF could account for as little as $33 \%$ (top-down from Cambaliza et al., 2015) or as much as $63 \%$ (inventory from Maasakkers et al., 2016) of total Marion County $\mathrm{CH}_{4}$ emissions. Other city point sources are comparatively small; the wastewater treatment facility located near SSLF contributes about 3-7 mol s${ }^{-1}$ (inventory from Lamb et al., 2016), and the transmissiondistribution transfer station at the Panhandle Eastern Pipeline (also known as a city gate and in this study abbreviated to PEP) is estimated to be about $1 \mathrm{~mol} \mathrm{~s}^{-1}$ (inventory from Lamb et al., 2016). The remaining $\mathrm{CH}_{4}$ sources, mainly from NG infrastructure leaks and livestock, are considered to be diffuse sources and are not well known. Potential sources of emissions related to NG activities include gas regulation meters, transmission and storage, distribution leaks, and compressed natural gas $(\mathrm{CNG})$ fleets. These diffuse NG sources account for $21 \%-67 \%$ of the city emissions or $20 \mathrm{~mol} \mathrm{~s}^{-1}$ (inventory from Maasakkers et al., 2016) to $64 \mathrm{~mol} \mathrm{~s}^{-1}$ (topdown from Cambaliza et al., 2015). Livestock emissions for Marion County are estimated to be around $1.5 \mathrm{~mol} \mathrm{~s}^{-1}$ (inventory from Maasakkers et al., 2016). These prior studies present conflicting conclusions regarding the magnitude of the diffuse $\mathrm{NG} \mathrm{CH}_{4}$ source in Indianapolis.

\section{Results and discussion}

\subsection{Inversion and city boundaries}

A significant portion of $\mathrm{CH}_{4}$ emissions across the US can be characterized by numerous relatively large point sources scattered throughout the country rather than by broad areas of smaller enhancements (Maasakkers et al., 2016). Because of this, the total emissions for a given domain can be very sensitive to how that domain is defined. A small increase or decrease in the domain area could add or remove a large point source and significantly impact the total emissions defined within the domain.
In the case of Indianapolis, this issue became apparent when the emissions were calculated using an atmospheric inversion model (Lamb et al., 2016; Lauvaux et al., 2016). The atmospheric inversion solved for fluxes in domain 1 (Fig. 2), which significantly increased the estimated emissions in comparison with the inventory values that were gathered mainly within Marion County (domain 2). When reduced to domain 2 , the inverse modeling emission estimate decreases to $107 \mathrm{~mol} \mathrm{~s}^{-1}$ (from about $160 \mathrm{~mol} \mathrm{~s}^{-1}$ ), which falls within an error bar of the Lamb et al. (2016) inventory estimate. This difference is significant and could at least partially explain the discrepancy shown in Fig. 1 between the emission values from the inventories and emission results from the inverse modeling. However, even the decreased inverse modeling estimate is about $91 \%$ higher than the inventories.

Additionally, the subject of the domain is relevant for airborne mass balance flights because a priori the magnitude and variability of background plume is unknown and could be easily influenced by upwind sources. The issue of background is discussed further in the next section.

\subsection{Variability in $\mathrm{CH}_{4}$ background}

Comparisons between criterion 1 and criterion $2 \mathrm{CH}_{4}$ background mole fractions as a function of wind speed and direction are visualized using frequency and bivariate polar plots (Fig. 4). Both backgrounds generally agree on the higher $\mathrm{CH}_{4}$ originating from the SW, SE, and $\mathrm{E}$ wind directions (Fig. 4c-f); however, the values themselves differ, especially when winds are from NW, SW, and SE. As background difference plots (Fig. $4 \mathrm{~g}-\mathrm{h}$ ) indicate, there is a noticeable variability between the magnitudes of the $\mathrm{CH}_{4}$ backgrounds, where criterion 2 , by design, typically has higher background mole fractions. The background differences, at a given hour, suggest that the $\mathrm{CH}_{4}$ field flowing into the city is heterogeneous, with differences between towers ranging from 0 to over 45 ppb (Fig. 4g). Because large gradients in $\mathrm{CH}_{4}$ background over the city could pose challenges for flux estimations using top-down methods such as inverse modeling and aircraft mass balance, it is imperative to establish whether the background differences vary randomly or systematically and how to choose a background to minimize these errors.

To further understand the nature of background variability we calculate the mean, standard deviation, and standard error of background hourly differences between criterion 2 and criterion 1 from November 2014 to December 2016 for each of the eight wind directions mentioned in Table 1. The results are shown in Fig. 5. Systematic bias is evident for the SE, S, SW, W, and NW wind sectors, whereas random error dominates the N, NE, and $\mathrm{E}$ wind directions. Wind directions showing statistically significant bias have mean biases ranging from 2 to $5 \mathrm{ppb}$, with values as large as $8 \mathrm{ppb}$ falling within the range of 2 times the standard error. The standard deviation plot indicates a potential background discrepancy 

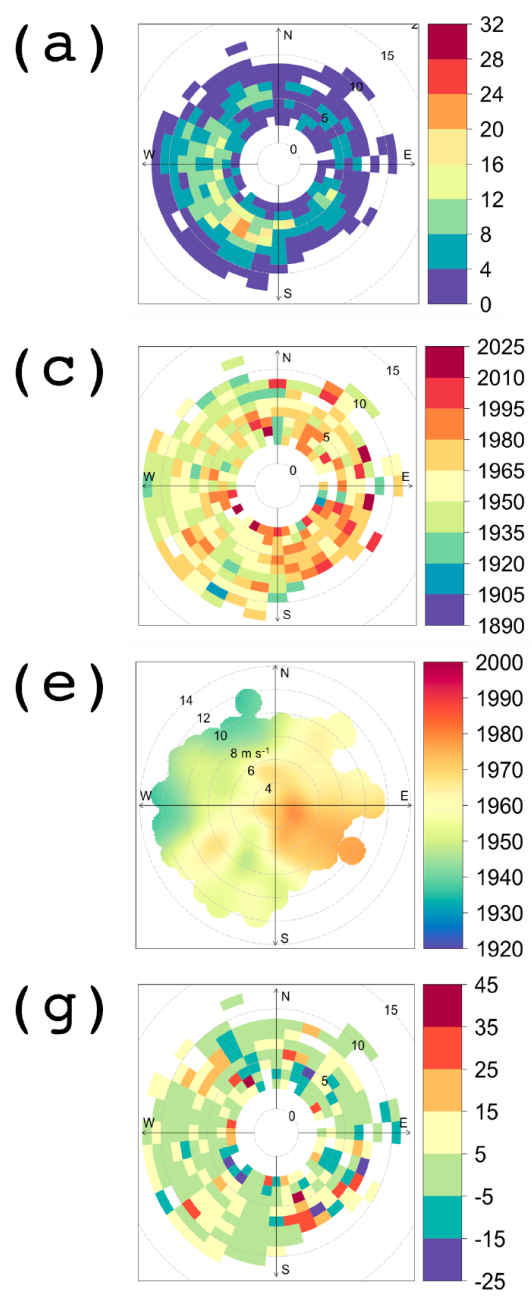

(b)

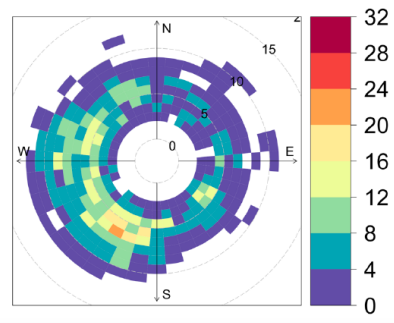

(d)

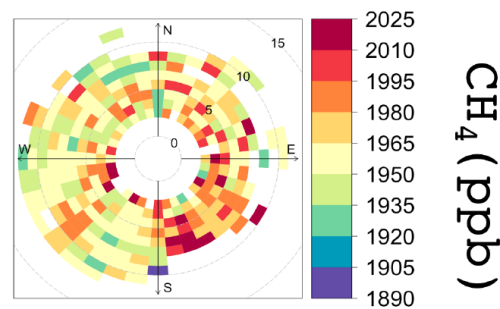

(f)

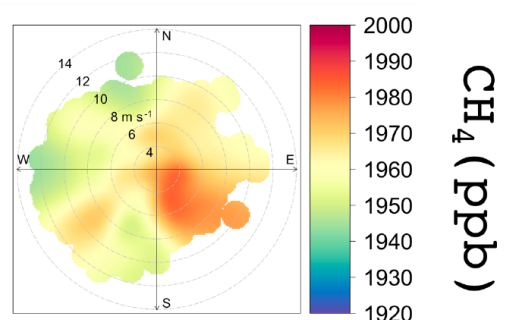

( h )

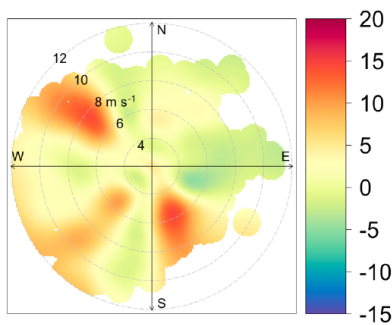

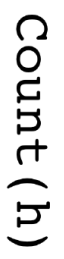

$\frac{0}{\frac{0}{0}}$

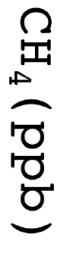

Figure 4. Frequency and bivariate polar plots of $\mathrm{CH}_{4}$ background for Indianapolis using data from 12:00-16:00 LST, November 2014 through December 2016 given two different criteria (Table 1). (a) Polar histogram indicating a number of hourly measurements available using criterion 1. (b) Same as (a) only for criterion 2. Differences between (a) and (b) are due to slight differences in data availability at the considered towers. (c) Polar frequency plot of the $\mathrm{CH}_{4}$ background using criterion 1. (d) Same as (c) only for criterion 2. (e) Polar bivariate plot of $\mathrm{CH}_{4}$ background using criterion 1. (f) Same as (e) only for criterion 2. (g) Polar frequency plot of difference between the backgrounds: criterion 2 - criterion 1. (h) Same as (g) but shown with a bivariate polar plot.

that can occur on any given day, where the $\mathrm{W}$ wind direction is the least variable, with 2 times the standard deviation close to $20 \mathrm{ppb}$, while SE wind direction is the most variable, with 2 times the standard deviation falling at about $50 \mathrm{ppb}$.

Random errors in the mole fractions of background differences (biases) are also important and are a function of the length of the data record. We quantify the random error in the $\mathrm{CH}_{4}$ background mole fraction differences using the bootstrap method by randomly sampling 2 to $150 \mathrm{~h}$ (small and large sample size) of the background $\mathrm{CH}_{4}$ differences for each of the wind directions with replacements (we make the assumption that our differences are independent since we eliminated lag 1 autocorrelation from the data). This subsampling experiment is repeated 5000 times (Efron and Tibshirani, 1986). The standard deviations of the mean (stan- dard error) of the 5000 simulated differences are calculated for each wind direction. The resulting standard errors of the city $\mathrm{CH}_{4}$ background differences, multiplied by 2 to represent the $95 \%$ confidence intervals, are shown as a function of the length of the data record in Fig. 6. Because random error falls as sample size grows it makes sense to assign a threshold indicating a minimum number of samples needed to achieve a theoretical precision for each wind direction.

One way to assign a required precision would be to make sure that the standard error (random error) reaches a point where it is less than the Indianapolis enhancement of about $12 \mathrm{ppb}$ (a higher estimate of the Indianapolis enhancement from Sect. 3.3) by a factor of 2 when combined with a bias (Table 2), meaning that the sum of bias and standard error must be at most $6 \mathrm{ppb}$. In this approach each wind direction 


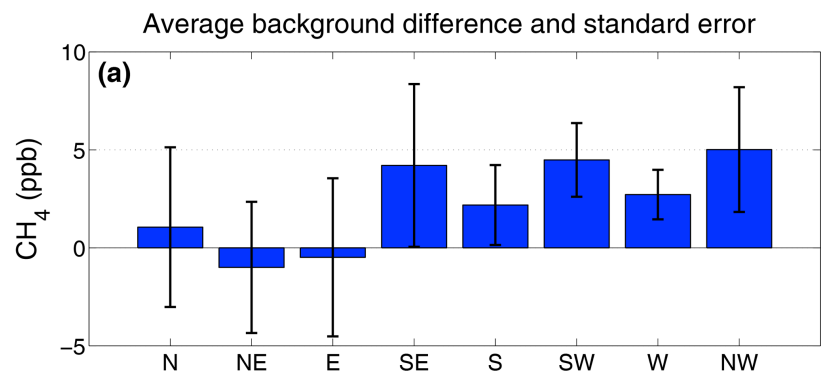

Average background difference and standard deviation

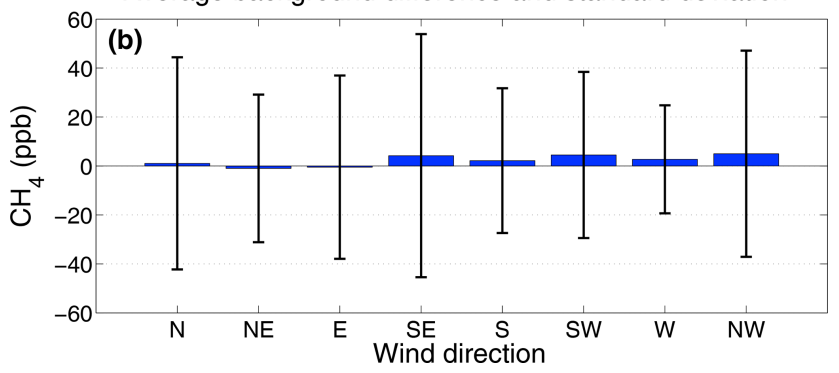

Figure 5. Average of the differences between criteria 2 and $1 \mathrm{CH}_{4}$ backgrounds at Indianapolis as a function of wind direction. These averages are generated from the same data that are used in Fig. 4 and reflect results shown in Fig. 4g. Error bars indicate in (a) 2 times the standard error and in (b) 2 times the standard deviation.

Table 2. A number of independent samples needed (column 4) to satisfy the combined requirement of $6 \mathrm{ppb}$ background error based on the sum of bias and random error (explained in Sect. 3.2) as a function of wind direction.

\begin{tabular}{lrrr}
\hline $\begin{array}{l}\text { Wind } \\
\text { direction }\end{array}$ & $\begin{array}{r}\text { Bias } \\
(\mathrm{ppb})\end{array}$ & $\begin{array}{r}\text { Threshold } \\
(\mathrm{ppb})\end{array}$ & $\begin{array}{r}\text { Samples } \\
\text { needed }\end{array}$ \\
\hline $\mathrm{N}$ & 1 & 5 & 74 \\
$\mathrm{NE}$ & 1 & 5 & 36 \\
$\mathrm{E}$ & 0.5 & 5.5 & 46 \\
$\mathrm{SE}$ & 4 & 2 & $>150$ \\
$\mathrm{~S}$ & 2 & 4 & 53 \\
SW & 4.5 & 1.5 & $>150$ \\
$\mathrm{~W}$ & 3 & 3 & 52 \\
NW & 5 & 1 & $>150$ \\
\hline
\end{tabular}

would have a different threshold because of the differences in biases. For instance, given this requirement the NW direction would need a random error of $1 \mathrm{ppb}$ since its bias is $5 \mathrm{ppb}$. For the NW direction, this threshold would require more than 150 samples. For the $\mathrm{N}$ direction on the other hand, where the bias is $1 \mathrm{ppb}$, the requirement is fulfilled when random error crosses $5 \mathrm{ppb}$ at 74 samples. Now we consider these random and systematic errors in $\mathrm{CH}_{4}$ background differences in the context of Indianapolis urban $\mathrm{CH}_{4}$ emissions.

For Indianapolis, using the INFLUX network, we estimated that depending on sample size (number of hours sampled) and wind direction, background gradient across the city
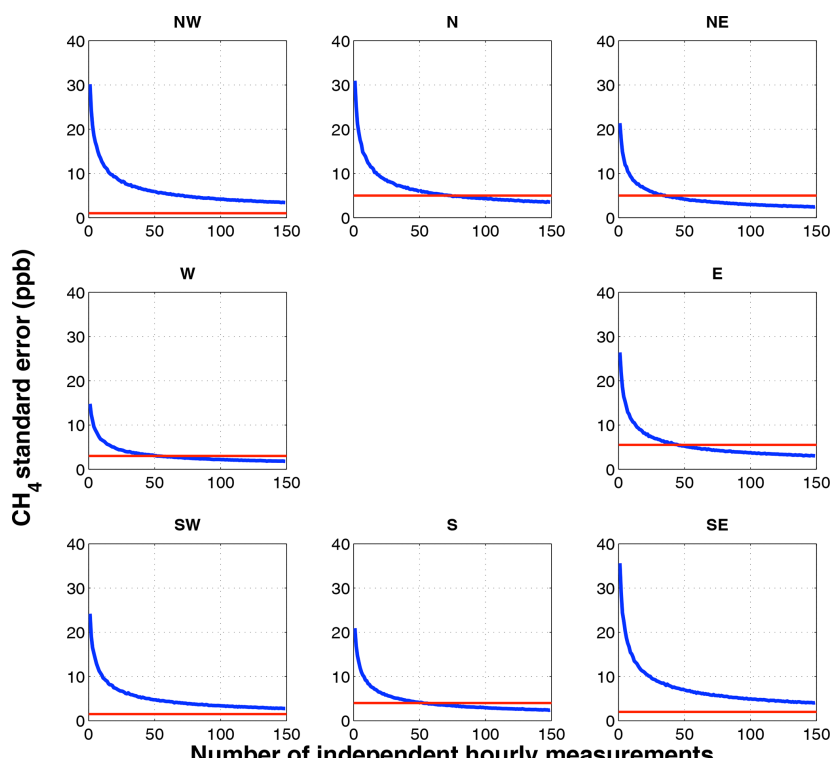

Figure 6. Bootstrap simulation of two times the standard error in Indianapolis $\mathrm{CH}_{4}$ background mole fraction differences (between criteria 2 and 1) as a function of sample size and wind direction (see text for details). Thresholds for each of the wind directions indicate a random error threshold needed for the background uncertainty to be within $50 \%$ of Indianapolis $\mathrm{CH}_{4}$ enhancement of $12 \mathrm{ppb}$.

over 12:00-16:00 LST could vary from 0 to about $50 \mathrm{ppb}$ (Fig. 5b). Given that the average afternoon $\mathrm{CH}_{4}$ enhancement of the city is around 8-12 ppb (Sect. 3.3; Fig. 7; Cambaliza et al., 2015; Miles et al., 2017a), the error on the estimated emissions could easily be over $100 \%$ if the analysis does not approach the issue of background with enough sampling. A sample size of about 50 independent hours significantly decreases background uncertainty for N, NE, E, S, and W wind directions and allows for a more accurate assessment of the $\mathrm{CH}_{4}$ emissions at Indianapolis. For $\mathrm{CH}_{4}$ sources with a significantly larger signal than their regional background, the mentioned background variability becomes less impactful on results, but because Indianapolis is a relatively small emitter of $\mathrm{CH}_{4}$, and because there are relatively large sources outside of the city, uncertainties due to background estimation are comparatively large. Our uncertainty assessment suggests that the highly variable $\mathrm{CH}_{4}$ emission values of Indianapolis from aircraft mass balance calculations shown in Fig. 1 are at least partially due to the variability in the urban $\mathrm{CH}_{4}$ background of Indianapolis.

\subsection{Temporal variability of methane enhancements and fluxes in Indianapolis}

Figure 7 presents average $\mathrm{CH}_{4}$ mole fraction enhancements and flux calculations (Eq. 4) at towers 8 and 13 for years 2014, 2016, and 2013-2016 (for the detailed methodology see Sect. 2.6). The years of 2014 and 2016 are chosen for 

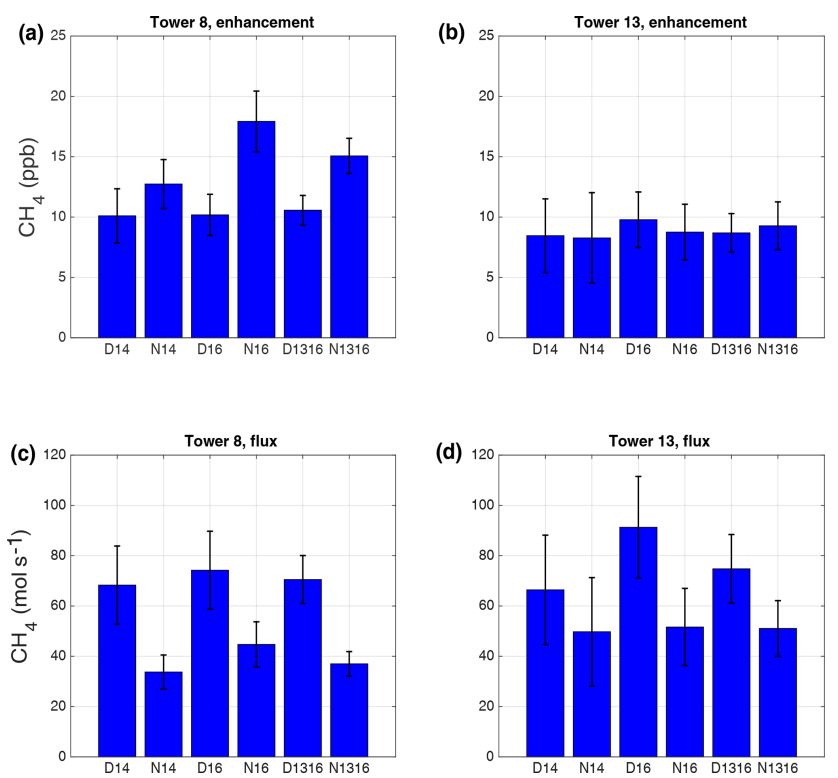

Figure 7. Averages of the daytime (D) and nighttime (N) $\mathrm{CH}_{4}$ enhancements and fluxes at INFLUX towers 8 and 13 for years 2014 (14), 2016 (16), and 2013-2016 (1316). The error bars represent the $95 \%$ confidence interval of each mean value. (a) Estimates of $\mathrm{CH}_{4}$ enhancements from tower 8. (b) Estimates of $\mathrm{CH}_{4}$ enhancements from tower 13. (c) Estimates of $\mathrm{CH}_{4}$ flux from tower 8. (d) Estimates of $\mathrm{CH}_{4}$ flux from tower 13 .

temporal comparison because they do not contain major BLH data gaps. The error bars in the figure show the standard error multiplied by 2 indicating $95 \%$ confidence interval of each average.

One of the more interesting features in Fig. 7 is a daynight variability of $\mathrm{CH}_{4}$ emissions at Indianapolis. The most prominent example of this feature is found in Fig. 7c, where the estimates for both years suggest that daytime emissions are approximately twice as large as the emissions at night. The decrease in the $\mathrm{CH}_{4}$ emissions at night also appears in tower 13, but the errors are too high in those estimates to make any definitive conclusions. A similar urban $\mathrm{CH}_{4}$ emissions diurnal variability is reported by Helfter et al. (2016) in their study of GHGs for London, UK, where they attribute diurnal variation of $\mathrm{CH}_{4}$ emissions to the NG distribution network activities, fugitive emissions from NG appliances, and temperature-sensitive $\mathrm{CH}_{4}$ emission sources of biogenic origin (such as a landfill). Taylor et al. (2018) suggest that $\mathrm{CH}_{4}$ emissions from landfills exhibit a diurnal cycle with higher emissions in the early afternoon and 30\%-40\% lower emissions at night.

With regard to yearly temporal variability we are only able to compare years 2014 and 2016 due to limited BLH data for other years. Results from both towers suggest that Indianapolis overall $\mathrm{CH}_{4}$ emissions did not change significantly between 2014 and 2016. Although it is important to be cautious about interpreting actual flux estimations given the as- sumptions mentioned in Sect. 2.6, it is interesting to note that the flux values from both towers average to about $70 \mathrm{~mol} \mathrm{~s}^{-1}$, which puts our value right in between inventory and inversion estimates shown in Fig. 1. If we assume that SSLF emissions are generally known (GHG reporting program) that would indicate that emissions from NG distribution are likely to be about $14 \mathrm{~mol} \mathrm{~s}^{-1}(70 \%)$ higher than what both of the inventories currently estimate but within the error bars of the Lamb et al. (2016) inventory calculation. Another possible scenario is that SSLF emissions are higher than what is currently assumed. Given these complexities, uncertainty regarding the exact emissions from NG distribution at Indianapolis still remains.

\subsection{Methane sources in Indianapolis}

Bottom-up emission inventories have difficulty tracking changes in sources over time. Our continuous tower network observations can monitor temporal and spatial variability in sources of $\mathrm{CH}_{4}$ in Indianapolis. To do so we employ the aforementioned bivariate polar plots to verify known sources and potentially identify unknown sources across the city. We compare two time periods, 2014-2015 (two full years) and 2016. Figure 8 displays bivariate polar plots of $\mathrm{CH}_{4}$ enhancements using criterion 1 background at 9 INFLUX towers in Indianapolis over the two years of 2014 and 2015. Figure 9 shows the same plot, but for the year 2016. Here we have separated 2016 from 2014-2015 because of different results noted during these times.

The images reveal that the most consistent and strongest source in the city is the SSLF. This is most evident from the $40+\mathrm{ppb} \mathrm{CH}_{4}$ enhancements detected at towers 7, 10, and 11 coming from the location of the SSLF (by triangulation). Enhancements from the landfill appear to also be detectable at towers 2, 4, 5, and 13. Based on these observations it can be concluded that there are no other point sources in Marion County comparable in size to the SSLF. A small fraction of the SSLF plume is likely due to the co-located wastewater facility, but the inventory estimates suggest that the wastewater treatment facility is responsible for no more than $7 \%$ of this plume (Cambaliza et al., 2015; Maasakkers et al., 2016). The PEP, located in the northwestern section of the city, may be partially responsible for a plume of $5-10 \mathrm{ppb}$ at towers 5 and 11. However, the plume is less detectable using the criterion 2 background value that has higher background (using tower 8 as a background) from the NW wind direction (not shown), adding uncertainty to the true magnitude of the enhancement from this source. The same is true for towers 2 and 13, which have pronounced plumes when winds are from the NW with the criterion 1 background, but when background 2 is used these plumes vanish (not shown). Such inconsistency makes it difficult to attribute these plumes to a specific source.

Another important point is the cluster of large enhancements surrounding tower 10 in 2014-2015. Because no other tower sees these enhancements (at least at comparable mag- 


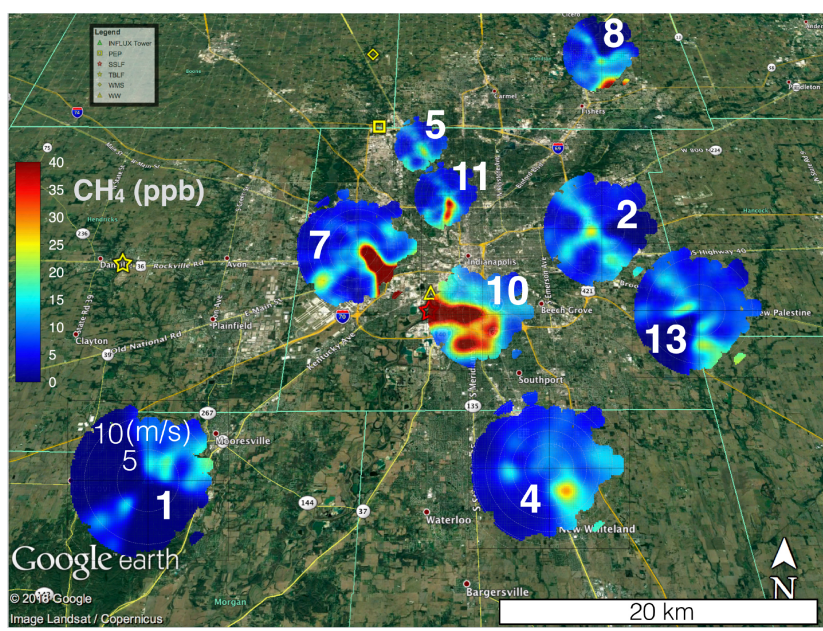

Figure 8. () Google Earth image overlaid with bivariate polar plots (Sect. 2.5) of the $\mathrm{CH}_{4}$ enhancements at nine INFLUX towers in Indianapolis using the criterion 1 background (Table 1) for the full years of 2014 and 2015 over the afternoon (12:00-16:00 LST). The wind speed scale is only labeled at site 1 ; other sites follow the same convention. The legend indicates known sources of $\mathrm{CH}_{4}$ : Panhandle Eastern Pipe Line (PEP), South Side landfill (SSLF), Twin Bridges landfill (TBLF), Waste Management Solutions (WMS), and a wastewater treatment facility (WW). The known magnitudes of sources that are in Marion County (PEP, SSLF, and WW) are reported in Sect. 2.7. Magnitudes of TBLF and WMS according to EPA are approximately $5 \mathrm{~mol} \mathrm{~s}^{-1}$. The largest known source on the map is SSLF.

nitudes), we believe that they are the result of nearby NG leaks. These plumes are not consistent temporally or spatially as they mostly disappear in 2016 , potentially indicating that they are transient and localized NG distribution leaks. It is difficult to ascertain the exact combined magnitude of these leaks since they mix together with SSLF into an aggregated city plume when observed from downwind towers such as 8 and 13. None of the individual leaks appears to be similar in magnitude to the emissions that originate from SSLF. Diffuse NG emissions comparable to the SSLF source (Lamb et al., 2016) may exist. Our flux estimations at towers 8 and 13 , however, imply that the magnitude of the NG diffuse source suggested by the top-down analyses in Cambaliza et al. (2015) and Lamb et al. (2016) are probably overestimates (see Sect. 3.3). We hypothesize that the relatively high Indianapolis $\mathrm{CH}_{4}$ emissions (see Fig. 1) reported by Cambaliza et al. (2015) could be a result of random errors in upwind conditions (see Sect. 3.2) influencing the small number of airborne flux estimates.

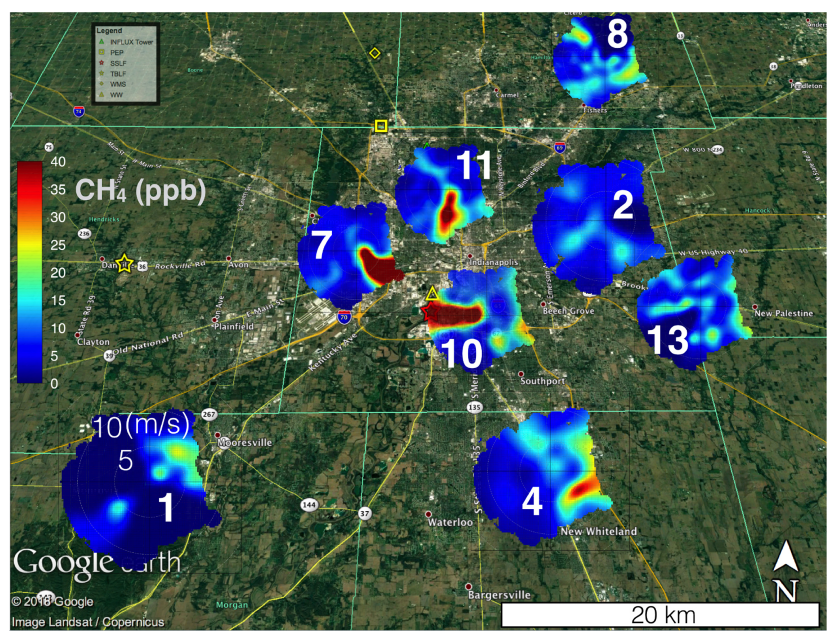

Figure 9. (C) Google Earth image overlaid with bivariate polar plots (Sect. 2.5) of the $\mathrm{CH}_{4}$ enhancements at nine INFLUX towers in Indianapolis using the criterion 1 background (Table 1) for the year 2016 over the afternoon (12:00-16:00 LST). The wind speed scale is only labeled at site 1; other sites follow the same convention. The legend indicates known sources of $\mathrm{CH}_{4}$ : Panhandle Eastern Pipe Line (PEP), South Side landfill (SSLF), Twin Bridges landfill (TBLF), Waste Management Solutions (WMS), and a wastewater treatment facility (WW). The known magnitudes of sources that are in Marion County (PEP, SSLF, and WW) are reported in Sect. 2.7. Magnitudes of TBLF and WMS according to EPA are approximately $5 \mathrm{~mol} \mathrm{~s}^{-1}$. The largest known source on the map is SSLF.

\section{Conclusions}

We have examined four potential contributions to discrepancies between urban top-down and bottom-up estimates of $\mathrm{CH}_{4}$ emissions from Indianapolis: domain definition, heterogeneous background mole fractions, temporal variability in emissions, and sources missing from inventories. Results indicate that the urban domain definition is crucial for the comparison of the emission estimates among various methods. Our atmospheric inverse flux estimates for Marion County, which is similar to the domain that is analyzed by inventory and airborne mass balance methodologies (Mays et al., 2009; Cambaliza et al., 2014; Lamb et al., 2016), is $107 \mathrm{~mol} \mathrm{~s}^{-1}$ compared to the $160 \mathrm{~mol} \mathrm{~s}^{-1}$ that is estimated for the larger domain (Hestia inventory domain; Gurney et al., 2012). This partially explains higher emissions in inverse modeling estimates shown by Lamb et al. (2016); however, $107 \mathrm{~mol} \mathrm{~s}^{-1}$ is still $91 \%$ higher than what EPA and Lamb et al. (2016) find in their inventories (Fig. 1).

To better understand background variability at Indianapolis two different but acceptable background estimates, based on specific criteria for each wind direction, and their differences are used to assess the heterogeneity of the $\mathrm{CH}_{4}$ background at Indianapolis. Background criterion 1 looks for a tower that is consistently lower than other towers, while background criterion 2 picks a tower that is outside of Marion 
County domain and is not downwind of any nearby sources as determined by the EPA 2012 inventory. We focus on midday atmospheric conditions to avoid the complexities of vertical stratification in the stable boundary layer. The midday Indianapolis atmospheric $\mathrm{CH}_{4}$ mole fraction background is shown to be heterogeneous, with $2-5$ ppb statistically significant biases for the NW, W, SW, S, and SE wind directions. Random errors of background differences are a function of sample size and decrease as a number of independent samples increase. Small sample sizes, such as a few hours of data from a single point, are prone to random errors on the order of $10-30 \mathrm{ppb}$ in the $\mathrm{CH}_{4}$ background, similar to the magnitude of the total enhancement from the city of Indianapolis, which is estimated to be on average around 10-12 ppb. Longer-term sampling and/or more extensive background sampling are necessary to reduce the random errors. Sample size required to reduce random errors of background differences to an acceptable value for flux calculation is largely dependent on a wind direction. Both bias (long-term average of background differences) and its random error are important when estimating total background uncertainty. The results indicate that the $\mathrm{N}, \mathrm{NE}, \mathrm{E}, \mathrm{S}$, and $\mathrm{W}$ wind directions are more favorable for flux estimation and would require multiple days of measurements (e.g., about 50 independent hours of measurements) to reduce background uncertainty to about $6 \mathrm{ppb}$, which is half the magnitude of the typical $\mathrm{CH}_{4}$ enhancement from Indianapolis. The remaining wind directions would require over 150 independent hourly measurements to achieve similar precision. We also estimate that depending on a wind direction for any given hour the spatial variability in background can be anywhere from 0 to $50 \mathrm{ppb}$. This uncertainty in the $\mathrm{CH}_{4}$ background may partially explain the Heimburger et al. (2017) finding of large variability in airborne estimates of Indianapolis $\mathrm{CH}_{4}$ emissions. Given many samples, the airborne studies converge to an average value of $\mathrm{CH}_{4}$ flux that is noticeably closer to the inventory estimates for Indianapolis than several of the individual estimates presented in Fig. 1.

Measurement and analysis strategies can minimize the impacts of these sources of error. Spatially extensive measurement of upwind $\mathrm{CH}_{4}$ mole fractions are recommended. For towers or other point-based measurements, multiple upwind measurement locations are clearly beneficial. For the aircraft mass balance approach, we recommend an upwind transect to be measured, lagged in time if possible, to provide a more complete understanding of the urban background conditions. Complex background conditions might suggest that data from certain days or wind directions should not be used for flux calculation. Finally, a mesoscale atmospheric modeling system informed with the locations of important upwind $\mathrm{CH}_{4}$ sources can serve as a powerful complement to the atmospheric data (Barkley et al., 2017). Such simulations can guide sampling strategies and aid in interpretation of data collected with moderately complex background conditions.

With regard to temporal variability, no statistically detectable changes in the emission rates were observed when comparing 2014 and $2016 \mathrm{CH}_{4}$ emissions. However, a large difference between day and night $\mathrm{CH}_{4}$ emissions was implied from a simple budget estimate. Night (20:0005:00 LST) emissions may be 2 times lower than the emissions during the afternoon (12:00-16:00 LST) hours. Because prior estimates of top-down citywide emissions are derived using afternoon-only measurements, overall emissions of Indianapolis may be lower than these studies suggest. This bias may be present in studies performed in other cities as well. Our study suggests that day-night differences in $\mathrm{CH}_{4}$ emissions must be understood if regional emission estimates are to be calculated correctly. Long-term, tower-based observations are an effective tool for understanding and quantifying multi-year variability in urban emissions.

One final point addressed in this study is the location of major $\mathrm{CH}_{4}$ sources in Indianapolis. Analysis of the INFLUX tower observations suggest a diffuse NG source that exceeds both of the inventory estimates by $70 \%$, but additionally our analysis shows that the discrepancy is less than that proposed by the highest values reported in Lamb et al. (2016) (see Fig. 1). Uncertainty remains regarding the magnitude of the diffuse NG source of $\mathrm{CH}_{4}$. The only major point source in the city is SSLF and it is observed at multiple towers. There is evidence for occasional point-source NG leaks, but they appear to be transient in time and limited in their strength.

Overall, assessment of the $\mathrm{CH}_{4}$ emissions at Indianapolis highlights a number of uncertainties that need to be considered in any serious evaluation of urban $\mathrm{CH}_{4}$ emissions. These uncertainties are amplified for Indianapolis since the enhancement signal from its $\mathrm{CH}_{4}$ emissions is comparable in magnitude to variability in the regional background flow and as our results show it may be difficult at times to distinguish noise in the background from the actual city emissions signal. The evaluation of larger $\mathrm{CH}_{4}$ sources may be easier with respect to separating signal from background. However, all of the points raised in this work will be nonetheless relevant and need to be addressed for our understanding of urban $\mathrm{CH}_{4}$ emissions to significantly improve.

Data availability. All of the data from the INFLUX tower network used in this article are available at https://doi.org/10.18113/D37G6P (Miles at al., 2017b).

Author contributions. NVB, KJD, and NLM developed the study and worked together on generating the main hypothesis of this work. They also wrote most of the paper. NVB wrote all of the codes and performed the analyses presented in this work as well as generating all of the figures. NLM and SJR helped with maintenance and gathering of the INFLUX tower data. They also wrote Sect. 2.2 of the paper. TL helped with the analysis presented in Fig. 1 and Sect. 3.1 concerning interpretation of the inversion modeling results from Lamb et al. (2016). Thomas Lauvaux also helped with repeating the inversion experiment for two different Indianapolis domains (Fig. 1). ZRB significantly contributed to discussions regarding the 
hypothesis and careful presentation of Sects. 2.6 and 3.3. TAB provided all of the lidar data and wrote the second part of Sect. 2.3 regarding the lidar and the methodology used to determine planetary boundary layer heights. He also contributed to Sects. 2.6 and 3.3.

Competing interests. The authors declare that they have no conflict of interest.

Special issue statement. This article is part of the special issue "The 10th International Carbon Dioxide Conference (ICDC10) and the 19th WMO/IAEA Meeting on Carbon Dioxide, other Greenhouse Gases and Related Measurement Techniques (GGMT-2017) (AMT/ACP/BG/CP/ESD inter-journal SI)". It is a result of the 10th International Carbon Dioxide Conference, Interlaken, Switzerland, 21-25 August 2017.

Acknowledgements. We would like to thank Bram Maasakkers for the helpful discussion regarding the EPA 2012 inventory and the relevant error structure. We also thank Paul Shepson and Brian Lamb for their useful input regarding airborne mass balance flights and the process of compiling an emissions inventory. Most importantly, we would like to acknowledge the significant contributions of both reviewers who rigorously examined our science and noticeably improved clarity of our article.

Financial support. This research has been supported by the National Institute of Standards and Technology (grant no. 70NANB10H245).

Review statement. This paper was edited by Neil Harris and reviewed by three anonymous referees.

\section{References}

Alvarez, R. A., Zavala-Araiza, D., Lyon, D. R., Allen, D. T., Barkley, Z. R., Brandt, A. R., Davis, K. J., Herndon, S. C., Jacob, D. J., Karion, A., Kort, E. A., Lamb, B. K., Lauvaux, T., Maasakkers, J. D., Marchese, A. J., Omara, M., Pacala, S. W., Peischl, J., Robinson, A. L., Shepson, P. B., Sweeney, C., Townsend-Small, A., Wofsy, S. C., and Hamburg, S. P.: Assessment of methane emissions from the U.S. oil and gas supply chain, Science, 361, 186-188, https://doi.org/10.1126/science.aar7204, 2018.

Arya, S. P.: Air pollution meteorology and dispersion, Oxford University Press New York, 1999.

Bakwin, P. S., Tans, P. P., Hurst, D. F., and Zhao, C.: Measurements of carbon dioxide on very tall towers: results of the NOAA/CMDL program, Tellus, 50B, 401-415, 1998.

Barkley, Z. R., Lauvaux, T., Davis, K. J., Deng, A., Miles, N. L., Richardson, S. J., Cao, Y., Sweeney, C., Karion, A., Smith, M., Kort, E. A., Schwietzke, S., Murphy, T., Cervone, G., Martins, D., and Maasakkers, J. D.: Quantifying methane emissions from natural gas production in north-eastern Pennsylvania, Atmos. Chem. Phys., 17, 13941-13966, https://doi.org/10.5194/acp-1713941-2017, 2017.

Bonin, T. A., Carroll, B. J., Hardesty, R. M., Brewer, W. A., Hajny, K., Salmon, O. E., and Shepson, P. B.: Doppler lidar observations of the mixing height in Indianapolis using an automated composite fuzzy logic approach, J. Atmos. Ocean. Technol., 35 , 473-490, https://doi.org/10.1175/jtech-d-17-0159.1, 2018.

Brandt, A. R., Heath, G. A., Kort, E. A., O’Sullivan, F., Pétron, G., Jordaan, S. M., Tans, P., Wilcox, J., Gopstein, A. M., Arent, D., Wofsy, S., Brown, N. J., Bradley, R., Stucky, G. D., Eardley, D., and Harriss, R.: Methane leaks from North American natural gas systems, Science, 343, 733-735, https://doi.org/10.1126/science.1247045, 2014.

Cambaliza, M., Shepson, P., Bogner, J., Caulton, D., Stirm, B., Sweeney, C., Montzka, S., Gurney, K., Spokas, K., and Salmon, O.: Quantification and source apportionment of the methane emission flux from the city of Indianapolis, Elem. Sci. Anth., 3, 000037, 2015

Cambaliza, M. O. L., Shepson, P. B., Caulton, D. R., Stirm, B., Samarov, D., Gurney, K. R., Turnbull, J., Davis, K. J., Possolo, A., Karion, A., Sweeney, C., Moser, B., Hendricks, A., Lauvaux, T., Mays, K., Whetstone, J., Huang, J., Razlivanov, I., Miles, N. L., and Richardson, S. J.: Assessment of uncertainties of an aircraft-based mass balance approach for quantifying urban greenhouse gas emissions, Atmos. Chem. Phys., 14, 9029-9050, https://doi.org/10.5194/acp-14-9029-2014, 2014

Carslaw, D. C. and Beevers, S. D.: Characterising and understanding emission sources using bivariate polar plots and k-means clustering, Environ. Modell. Softw., 40, 325-329, https://doi.org/10.1016/j.envsoft.2012.09.005, 2013.

Carslaw, D. C. and Ropkins, K.: openair - An R package for air quality data analysis, Environ. Modell. Softw., 27-28, 52-61, https://doi.org/10.1016/j.envsoft.2011.09.008, 2012.

Ciais, P., Sabine, C., Bala, G., Bopp, L., Brovkin, V., Canadell, J., Chhabra, A., DeFries, R., Galloway, J., and Heimann, M.: Carbon and other biogeochemical cycles, in: Working Group I Contribution To The IPCC Fifth Assessment Report. Climate Change 2013 - The Physical Science Basis, edited by: Stocker, T. F., Qin, D., Plattner, G., Tignor, M., Allen, S., Boschung, J., Nauels, A., Xia, Y., Bex, V., and Midgley, P., Cambridge Univ. Press, 465570, 2013.

Davis, K. J., Deng, A., Lauvaux, T., Miles, N. L., Richardson, S. J., Sarmiento, D. P., Gurney, K. R., Hardesty, R. M., Bonin, T. A., and Brewer, W. A.: The Indianapolis Flux Experiment (INFLUX): A test-bed for developing urban greenhouse gas emission measurements, Elem. Sci. Anth., 5, p. 21, 2017.

Deng, A., Lauvaux, T., Davis, K. J., Gaudet, B. J., Miles, N., Richardson, S. J., Wu, K., Sarmiento, D. P., Hardesty, R. M., and Bonin, T. A.: Toward reduced transport errors in a high resolution urban $\mathrm{CO}_{2}$ inversion system, Elem. Sci. Anth., 5, p. 20, 2017.

Efron, B. and Tibshirani, R.: Bootstrap methods for standard errors, confidence intervals, and other measures of statistical accuracy, Statist. Sci., 1, 54-75, https://doi.org/10.1214/ss/1177013815, 1986.

European Commission Joint Research Centre, Netherlands Environmental Assessment Agency: Emission Database for Global Atmospheric Research (EDGAR), Release Version 4.2, available at: http://edgar.jrc.ec.europa.eu (last access: 9 April 2020), 2010. 
Gurney, K. R., Razlivanov, I., Song, Y., Zhou, Y., Benes, B., and Abdul-Massih, M.: Quantification of fossil fuel $\mathrm{CO}_{2}$ emissions on the building/street scale for a large U.S. city, Environ. Sci. Technol., 46, 12194-12202, https://doi.org/10.1021/es3011282, 2012.

Hanna, S. R., Briggs, G. A., and Hosker Jr., R. P.: Handbook on atmospheric diffusion, National Oceanic and Atmospheric Administration, Oak Ridge, TN (USA), Atmospheric Turbulence and Diffusion Lab., 1982.

Heimburger, A. M., Harvey, R. M., Shepson, P. B., Stirm, B. H., Gore, C., Turnbull, J., Cambaliza, M. O., Salmon, O. E., Kerlo, A.-E. M., and Lavoie, T. N.: Assessing the optimized precision of the aircraft mass balance method for measurement of urban greenhouse gas emission rates through averaging, Elem. Sci. Anth., 5, p. 26, 2017.

Helfter, C., Tremper, A. H., Halios, C. H., Kotthaus, S., Bjorkegren, A., Grimmond, C. S. B., Barlow, J. F., and Nemitz, E.: Spatial and temporal variability of urban fluxes of methane, carbon monoxide and carbon dioxide above London, UK, Atmos. Chem. Phys., 16, 10543-10557, https://doi.org/10.5194/acp-16-105432016, 2016.

Hendrick, M. F., Ackley, R., Sanaie-Movahed, B., Tang, X., and Phillips, N. G.: Fugitive methane emissions from leak-prone natural gas distribution infrastructure in urban environments, Environ. Pollut., 213, 710-716, https://doi.org/10.1016/j.envpol.2016.01.094, 2016.

Hiller, R. V., Neininger, B., Brunner, D., Gerbig, C., Bretscher, D., Künzle, T., Buchmann, N., and Eugster, W.: Aircraft-based $\mathrm{CH}_{4}$ flux estimates for validation of emissions from an agriculturally dominated area in Switzerland, J. Geophys. Res.-Atmos., 119, 4874-4887, https://doi.org/10.1002/2013JD020918, 2014.

Hmiel, B., Petrenko, V. V., Dyonisius, M. N., Buizer, C., Smith A. M., Place, P. F., Harth, C., Beaudette, R., Hua, Q., Yang, B., Vimont, I., Michel, S. E., Severinghaus, J. P., Etheridge, D., Bromley, Schmitt, J., Faïn, X., Weiss, R. F., and Dlugokencky, E.: Preindustrial ${ }^{14} \mathrm{CH}_{4}$ indicates greater anthropogenic fossil $\mathrm{CH}_{4}$ emissions, Nature, 578, 409-412, https://doi.org/10.1038/s41586-020-1991-8, 2020.

Jackson, R. B., Down, A., Phillips, N. G., Ackley, R. C., Cook, C. W., Plata, D. L., and Zhao, K. G.: Natural gas pipeline leaks across Washington, DC, Environ. Sci. Technol., 48, 2051-2058, https://doi.org/10.1021/es404474x, 2014.

Jeong, S., Millstein, D., and Fischer, M. L.: Spatially explicit methane emissions from petroleum production and the natural gas system in California, Environ. Sci. Technol., 48, 5982-5990, https://doi.org/10.1021/es4046692, 2014.

Jeong, S., Newman, S., Zhang, J., Andrews, A. E., Bianco, L., Bagley, J., Cui, X., Graven, H., Kim, J., Salameh, P., LaFranchi, B. W., Priest, C., Campos-Pineda, M., Novakovskaia, E., Sloop, C. D., Michelsen, H. A., Bambha, R. P., Weiss, R. F., Keeling, R., and Fischer, M. L.: Estimating methane emissions in California's urban and rural regions using multitower observations, J. Geophys. Res.-Atmos., 121, 13031-013049, https://doi.org/10.1002/2016JD025404, 2016.

Jeong, S., Cui, X., Blake, D. R., Miller, B., Montzka, S. A., Andrews, A., Guha, A., Martien, P., Bambha, R. P., LaFranchi, B., Michelsen, H. A., Clements, C. B., Glaize, P., and Fischer, M. L.: Estimating methane emissions from biological and fossil-fuel sources in the San Francisco Bay Area, Geophys. Res. Lett., 44, 486-495, https://doi.org/10.1002/2016GL071794, 2017.

Karion, A., Sweeney, C., Kort, E. A., Shepson, P. B., Brewer, A., Cambaliza, M., Conley, S. A., Davis, K., Deng, A., Hardesty, M., Herndon, S. C., Lauvaux, T., Lavoie, T., Lyon, D., Newberger, T., Pétron, G., Rella, C., Smith, M., Wolter, S., Yacovitch, T. I., and Tans, P.: Aircraft-based estimate of total methane emissions from the Barnett Shale region, Environ. Sci. Technol., 49, 8124-8131, https://doi.org/10.1021/acs.est.5b00217, 2015

Kort, E. A., Eluszkiewicz, J., Stephens, B. B., Miller, J. B., Gerbig, C., Nehrkorn, T., Daube, B. C., Kaplan, J. O., Houweling, S., and Wofsy, S. C.: Emissions of $\mathrm{CH}_{4}$ and $\mathrm{N}_{2} \mathrm{O}$ over the United States and Canada based on a receptor-oriented modeling framework and COBRA-NA atmospheric observations, Geophys. Res. Lett., 35, L18808, https://doi.org/10.1029/2008GL034031, 2008.

Lamb, B. K., Cambaliza, M. O. L., Davis, K. J., Edburg, S. L., Ferrara, T. W., Floerchinger, C., Heimburger, A. M. F., Herndon, S., Lauvaux, T., Lavoie, T., Lyon, D. R., Miles, N., Prasad, K. R., Richardson, S., Roscioli, J. R., Salmon, O. E., Shepson, P. B., Stirm, B. H., and Whetstone, J.: Direct and indirect measurements and modeling of methane emissions in Indianapolis, Indiana, Environ. Sci. Technol., 50, 8910-8917, https://doi.org/10.1021/acs.est.6b01198, 2016.

Lauvaux, T., Miles, N. L., Deng, A., Richardson, S. J., Cambaliza, M. O., Davis, K. J., Gaudet, B., Gurney, K. R., Huang, J., O’Keefe, D., Song, Y., Karion, A., Oda, T., Patarasuk, R., Razlivanov, I., Sarmiento, D., Shepson, P., Sweeney, C., Turnbull, J., and $\mathrm{Wu}, \mathrm{K}$.: High-resolution atmospheric inversion of urban $\mathrm{CO}_{2}$ emissions during the dormant season of the Indianapolis Flux Experiment (INFLUX), J. Geophys. Res.-Atmos., 121, 52135236, https://doi.org/10.1002/2015JD024473, 2016.

Maasakkers, J. D., Jacob, D. J., Sulprizio, M. P., Turner, A. J., Weitz, M., Wirth, T., Hight, C., DeFigueiredo, M., Desai, M., Schmeltz, R., Hockstad, L., Bloom, A. A., Bowman, K. W., Jeong, S., and Fischer, M. L.: Gridded national inventory of U.S. methane emissions, Environ. Sci. Technol., 50, 13123-13133, https://doi.org/10.1021/acs.est.6b02878, 2016.

Mays, K. L., Shepson, P. B., Stirm, B. H., Karion, A., Sweeney, C., and Gurney, K. R.: Aircraft-based measurements of the carbon footprint of Indianapolis, Environ. Sci. Technol., 43, 7816-7823, https://doi.org/10.1021/es901326b, 2009.

McKain, K., Down, A., Raciti, S. M., Budney, J., Hutyra, L. R., Floerchinger, C., Herndon, S. C., Nehrkorn, T., Zahniser, M. S., Jackson, R. B., Phillips, N., and Wofsy, S. C.: Methane emissions from natural gas infrastructure and use in the urban region of Boston, Massachusetts, P. Natl. Acad. Sci. USA, 112, 19411946, https://doi.org/10.1073/pnas.1416261112, 2015.

Miles, N. L., Richardson, S. J., Lauvaux, T., Davis, K. J., Balashov, N. V., Deng, A., Turnbull, J. C., Sweeney, C., Gurney, K. R., and Patarasuk, R.: Quantification of urban atmospheric boundary layer greenhouse gas dry mole fraction enhancements in the dormant season: Results from the Indianapolis Flux Experiment (INFLUX), Elem. Sci. Anth., 5, p. 27, 2017a.

Miles, N. L., Richardson, S. J., Davis, K. J., and Haupt, B. J.: In-situ tower atmospheric measurements of carbon dioxide, methane and carbon monoxide mole fraction for the Indianapolis Flux (INFLUX) project, Indianapolis, IN, USA, Data set, The Pennsylvania State University Data Commons, University Park, Pennsylvania, USA, https://doi.org/10.18113/D37G6P, 2017b. 
Miller, S. M., Wofsy, S. C., Michalak, A. M., Kort, E. A., Andrews, A. E., Biraud, S. C., Dlugokencky, E. J., Eluszkiewicz, J., Fischer, M. L., Janssens-Maenhout, G., Miller, B. R., Miller, J. B., Montzka, S. A., Nehrkorn, T., and Sweeney, C.: Anthropogenic emissions of methane in the United States, P. Natl. Acad. Sci. USA, 110, 20018-20022, https://doi.org/10.1073/pnas.1314392110, 2013.

Myhre, G., Shindell, D., Bréon, F. M., Collins, W., Fuglestvedt, J., Huang, J., Koch, D., Lamarque, J. F., Lee, D., Mendoza, B., Nakajima, T., Robock, A., Stephens, G., Takemura, T., and Zhang, H.: Anthropogenic and natural radiative forcing, in: Climate Change 2013: The Physical Science Basis. Contribution of Working Group I to the Fifth Assessment Report of the Intergovernmental Panel on Climate Change, edited by: Stocker, T. F., Qin, D., Plattner, G. K., Tignor, M., Allen, S. K., Doschung, J., Nauels, A., Xia, Y., Bex, V., and Midgley, P. M., Cambridge University Press, Cambridge, UK, 659-740, 2013.

National Academies of Sciences and Medicine: Improving characterization of anthropogenic methane emissions in the United States, The National Academies Press, Washington, DC, 250 pp., 2018.

Nisbet, E. G., Dlugokencky, E. J., Manning, M. R., Lowry, D., Fisher, R. E., France, J. L., Michel, S. E., Miller, J. B., White, J. W. C., Vaughn, B., Bousquet, P., Pyle, J. A., Warwick, N. J., Cain, M., Brownlow, R., Zazzeri, G., Lanoisellé, M., Manning, A. C., Gloor, E., Worthy, D. E. J., Brunke, E.-G., Labuschagne, C., Wolff, E. W., and Ganesan, A. L.: Rising atmospheric methane: 2007-2014 growth and isotopic shift, Global Biogeochem. Cy., 30, 1356-1370, https://doi.org/10.1002/2016GB005406, 2016.

Nisbet, E. G., Manning, M. R., Dlugokencky, E. J., Fisher, R. E., Lowry, D., Michel, S. E., Myhre, C. L., Platt, S. M., Allen, G., Bousquet, 15 P., Brownlow, R., Cain, M., France, J. L., Hermansen, O., Hossaini, R., Jones, A. E., Levin, I., Manning, A. C., Myhre, G., Pyle, J. A., Vaughn, B. H., Warwick, N. J., and White, J. W. C.: Very Strong Atmospheric Methane Growth in the 4 Years 2014-2017: Implications for the Paris Agreement, Global Biogeochem. Cy., 33, 318-342, https://doi.org/10.1029/2018GB006009, 2019.

Richardson, S. J., Miles, N. L., Davis, K. J., Lauvaux, T., Martins, D. K., Turnbull, J. C., McKain, K., Sweeney, C., and Cambaliza, M. O. L.: Tower measurement network of in-situ $\mathrm{CO}_{2}, \mathrm{CH}_{4}$, and $\mathrm{CO}$ in support of the Indianapolis FLUX (INFLUX) Experiment, Elem. Sci. Anth., 5, p. 59, 2017.

Sarmiento, D. P., Davis, K. J., Deng, A., Lauvaux, T., Brewer, A., and Hardesty, M.: A comprehensive assessment of land surfaceatmosphere interactions in a WRF/Urban modeling system for Indianapolis, IN, Elem. Sci. Anth., 5, p. 23, 2017.

Saunois, M., Jackson, R. B., Bousquet, P., Poulter, B., and Canadell, J. G.: The growing role of methane in anthropogenic climate change, Environ. Res. Lett., 11, 120207, https://doi.org/10.1088/1748-9326/11/12/120207, 2016.
Schuh, A. E., Lauvaux, T., West, T. O., Denning, A. S., Davis, K. J., Miles, N., Richardson, S., Uliasz, M., Lokupitiya, E., Cooley, D., Andrews, A., and Ogle, S.: Evaluating atmospheric $\mathrm{CO}_{2}$ inversions at multiple scales over a highly inventoried agricultural landscape, Global Change Biol., 19, 1424-1439, https://doi.org/10.1111/gcb.12141, 2013.

Taylor, D. M., Chow, F. K., Delkash, M., and Imhoff, P. T.: Atmospheric modeling to assess wind dependence in tracer dilution method measurements of landfill methane emissions, Waste Manage., 73, 197-209, https://doi.org/10.1016/j.wasman.2017.10.036, 2018.

Townsend-Small, A., Tyler, S. C., Pataki, D. E., Xu, X., and Christensen, L. E.: Isotopic measurements of atmospheric methane in Los Angeles, California, USA: Influence of "fugitive" fossil fuel emissions, J. Geophys. Res.-Atmos., 117, 1-11, https://doi.org/10.1029/2011JD016826, 2012.

Turnbull, J. C., Sweeney, C., Karion, A., Newberger, T., Lehman, S. J., Tans, P. P., Davis, K. J., Lauvaux, T., Miles, N. L., Richardson, S. J., Cambaliza, M. O., Shepson, P. B., Gurney, K., Patarasuk, R., and Razlivanov, I.: Toward quantification and source sector identification of fossil fuel $\mathrm{CO}_{2}$ emissions from an urban area: Results from the INFLUX experiment, J. Geophys. Res.-Atmos., 120, 292-312, https://doi.org/10.1002/2014JD022555, 2015.

Turnbull, J. C., Karion, A., Davis, K. J., Lauvaux, T., Miles, N. L., Richardson, S. J., Sweeney, C., McKain K., Lehman, S. J., Gurney, K., Patarasuk, R., Jianming L., Shepson, P. B., Heimburger A., Harvey, R., and Whetstone, J.: Synthesis of urban $\mathrm{CO}_{2}$ emission estimates from multiple methods from the Indianapolis Flux Project (INFLUX), Environ. Sci. Technol., 53, 287-295, https://doi.org/10.1021/acs.est.8b05552, 2019.

U.S. EPA (Environmental Protection Agency): Inventory of U.S. Greenhouse Gas Emissions and Sinks: 1990-2011, Technical Report EPA 430-R-13-001, Environmental Protection Agency, Washington, 505 pp., 2013.

Van De Wiel, B. J. H., Moene, A. F., Jonker, H. J. J., Baas, P., Basu, S., Donda, J. M. M., Sun, J., and Holtslag, A. A. M.: The minimum wind speed for sustainable turbulence in the nocturnal boundary layer, J. Atmos. Sci., 69, 3116-3127, https://doi.org/10.1175/jas-d-12-0107.1, 2012.

Wunch, D., Wennberg, P. O., Toon, G. C., Keppel-Aleks, G., and Yavin, Y. G.: Emissions of greenhouse gases from a North American megacity, Geophys. Res. Lett., 36, L15810, https://doi.org/10.1029/2009GL039825, 2009.

Zavala-Araiza, D., Lyon, D. R., Alvarez, R. A., Davis, K. J., Harriss, R., Herndon, S. C., Karion, A., Kort, E. A., Lamb, B. K., Lan, X., Marchese, A. J., Pacala, S. W., Robinson, A. L., Shepson, P. B., Sweeney, C., Talbot, R., Townsend-Small, A., Yacovitch, T. I., Zimmerle, D. J., and Hamburg, S. P.: Reconciling divergent estimates of oil and gas methane emissions, P. Natl. Acad. Sci., 112 15597-15602, https://doi.org/10.1073/pnas.1522126112, 2015. 